lyer veins. She was as white as the sheets she lay between, was vomiting, and her urine confirmed the diagnosis made by the attendants. Before going back to Boston to get instruments to transfuse with, the senior writer sat down beside her, and, taking a diet list from his pocket, asked her if she could eat the different foods as named thereon. She said "No" till tripe was mentioned, and replied that she could eat that. So it was ordered. On returning with instruments the next day, he was told that there was no need of operating, as the patient had retained the tripe and was better. In March, 1886, we were in this neighbourhood operating on a case of uterine fibroid. The father expressed to the son a desire to see if this patient was alive, and on calling on her attending physician learned that she was, and on visiting her, found a large, florid woman, who said

"that she was not much for work, but was far from being dead." It seems that she lived on tripe and milk warm from the cow, with other animal food, for over two years, and by that time the evidence of Bright's disease had gradually and wholly disappeared from the urine.

CASE 9.-Some years ago, Miss A. B-, aged twentyfour years, was put on strict diet for her fibroid, which was of some years' standing, monolobed, interstitial, and hard; it invested the whole nterus, and extended beyond the umbilicus. She ate beef mostly, with clear tea and coffee, and took a simple tonic. It was much against her appetite, but, as she was a woman of few words and of a determined will, and had confidence in her medical adviser, she persevered until the uterine fibroid had all disappeared, and she remains to-day in perfect health. At present, in handling these cases of uterine fibroids both diet and galvanism are employed, the latter according to the rules laid down by the senior writer in 1871 . No one can say that this case was cured by the menopause, as so many medical agnostics as to the curability of uterine fibroids by either galvanism or food, or both, claim.

CASE 10 (1882).-Mr. H. L. H-, a small, not robust man, over sixty years of age, for many years had difficult digestion, caused by over-feeding upon vegetable food, so that the stomach was distended, wall infiltrated and hardened, causing a fibroid condition of the organ. When seen by the senior writer, he had been under treatricent by Dr. Salisbury with hot water, chopped beef diet, stomachic medicines, \&c. He ran down rapidly under the treatment, vomiting often and severely; throat sore and deglutition difficult; emaciation; weakness; some fever at times. He hat fainting fits, and appeared so moribund that his wife thought he would die in her arms. His hands, feet, and legs were cold ; circulation feeble; stomach distress great ; mind clear and tractable. There was also complete dulness on percussion over the hepatic region; the abdomen empty; walls drawn towards spine, flat, hard, not tender. He took no food by the mouth, but milk by the rectum. Was given nitric acid baths, one teaspoonful to one pint of warm water, night and morning; biniodide of mercury, $1_{10}^{\frac{1}{10}}$ gr., was given twice a day; one grain of the sulphate of quinine was sprinkled once in two hours on the tongue, which was white and coated. Compress of linen cloth wet in the nitric acid bath was placed over the hepatic region and kept till the skin was red. Though the romiting conbinued for a little time, the effect of the rectal aliment told. The alministration of mercury was followed by a diminution of the liver dulness. Soon he was able to take beef essence by the mouth; though he had no appetite, still he kept taking it, and by degrees increased the aroount till the essence of six pounds of beef daily was used by oral and rectal alimentation. Moving very carefully, the rectal administration was given up and the beef essence continued by the mouth. The case slowly improved, the urine showing less and less reaction of bile, the dulness of the liver running abreast, with the exception of a few days-that is, the dulness diminished with the diminution of bile in the urine. In the course of six weeks the appetite returned, the former treatment was resumed, and he remains cured (1889).

CASES 11, 12, and 13 were all suffering from Bright's disease in 1878,1880 , and 1884. In Cases 11 and 12 the patients were each about sixty years of age, and in Case 13 twentyfour years old. All were practically treated on the same plans, and all are liere to-day for your inspection as cases of cures of a so-called incurable disease.

CASE 16 (1876).-A middle-aged mother of a large family lay sick in bed of great grief at the loss of her last surviving daughter, who had died from the effects of the perforation of the vermiform appendix by an orange seed. There were present cardiac hypertrophy and insufficiency of the left auriculo-ventricular valve, with severe attacks of angina pectoris, when it seemed that death was near. The objective lesions other than those named were retroversion, engorgement, hardening, and eversion of the os uteri, and behind the uterus four small, hard, marble-like tumours; very severe pain, sharp and stinging, in the pelvis mostly; profuse vaginal discharge, not bloody; menorrhagia. Added to this there was loss of appetite so complete that everything in the nature of food was loathed, even milk being repulsive ; loss of flesh and strength, being unable to rise erect for ninety days; inability to lie on either side for most of the time; nausea; legs cold and sweaty up to the knees; ofttimes great stomach distress, with wind colic; urine high-coloured and of a rank smell, as if putrid; bowels constipated; a terrible feeling of nervous restlessness, causing her to move her feet rapidly up and down in the bed; visitors coming and assuring her by their looks and actions that she was about to die. Added to this there was cancer in her family, her father having died of cancer of the stomach, and her maternal grandmother of cancer of the breast. She was put on general and local treatment, and it was faithfully carried out in connexion with good nursing. but she gradually grew worse, until, at the expiration of three months, the symptoms were so alarming that the senior writer was obliged to take strong and decisive grounds, and to tell her, "You must eat or die of cancer of the womb. Make up your mind to one or the other." She decided to live and to eat; eating against her appetite, but with her intellect and reason and the advice of her medical attendant. She began with tender loin steak, broiled and cut up very fine. The most she could take at first was a quantity represented by two teaspoonfuls; these she swallowed by a desperate effort, her stomach rising against it. She was fed every four hours. Even after she had fed thus for weeks she felt she would rather die almost than eat, but battled against appetite by sheer force of will. The only way she could get down the beef was by swallowing one mouthful of lager beer, which was the only article which did not go against the stomach. The quantity of meat was increased gradually, and she was fed two months against the appetite. The nausea, however, left in about three or four weeks, and at this time she was able to be moved, and was placed in a Cutter invalid chair part of the day. After two months of feeding she was taken carefully to the sea. shore, and there she began to get an appetite, but it took one year before she could walk 500 feet. This patient did not fear death, but the form of it. The results obtained by food are in this case :-1. Heart normal in size. 2. Valvular insufficiency hardly perceivable. 3. Angina pectoris gone. 4. Uterine disease relieved; tumours disappeared; uterus mobile discharges normal. 5. Urine clear as champagne, specific gravity 1015-1020; no odour; no deposit on cooling. 6. Restoration to active duties as housekeeper and mother of the family. No medicine was given after the food treatment, save Hoffmann's anodyne when she had palpitation of the heart and difficulty in breathing. When we state that this case is here to-day, we think our hearers will admit that we have a living argument that we cannot ignore as to the curability of chronically diseased tissues. As the time is short, we will give no more histories, and proceed to the closing section of this contribution.

(To be concluded.)

\section{THE ABDOMINAL DISTENSION OF TYPHOID FEVER: ITS DANGERS AND TREATMENT.}

BY T. J. MACLAGAN, M.D., M.R.C.P.,

PIISICLIN TO THEIR ROYAL HIGHNESSES PRINCE AND PRINCESS CHRISTIAN.

AmoNG the many complications which tend to increase the dangers and anxieties inseparable from a severe attack of typhoid fever, none are more formidable than those which are the direct outcome of the bowel lesion. Among the dangers thus induced, none causes more anxiety, or more gravely affects our prognosis, than the extreme abdominal distension with which in severe cases we every now and then have to deal. A moderate amount of tympanites is a common symptom, and does not call for special treatment, but in severe cases it may become immoderate; the abdo. 
minal distension may be so great as to not only cause considerable distress, but, by its upward pressure on the diaphragm, to materially increase the danger of an already sufficiently grave illness. What adds to the gravity of this complication is the fact that it comes on late in the case, when the patient is already pulled down by two, three, or more weeks of fever. The condition essentially consists in great distension of the large bowel. Sloughs and sloughy discharges from the lesion in the small bowel have been slipping through the ileo-colic valve into the cæcum. As a rule, the diarrhoea which accompanies this process leads to their early discharge by stool ; but they may be detained in the cxcum or colon, or if very abundant may not be got rid of with sufficient rapidity to prevent the colon from getting distended by the gas formed during their rapid decomposition. The evil is constantly being added to by the descent of sloughs and putrid discharges from the ileum, and by-and-by the bowel gets paralysed from overdistension. The condition is not unlike that which has frequently to be dealt with in the case of the bladder; and, as in these cases of bladder distension in the typhoid state, a certain amount of urine may dribble away, occasionally leading the attendants to think that the bladder has been relieved, so in these cases of distended bowel a certain amount of flatus and fluid may pass away without any real relief being given. So long as the muscular coat of the bowel retains the power to contract the danger from distension of the colon is not imminent, sund relief may be given by the administration of a stimulant enema-turpentine, carbolic acid, \&c. But the distension may be so great as to paralyse the muscular coat of the bowel. Under such circumistances no enema can make the bowel act; and from such treatment no good, and possible harm, may result. When such a point is reached the patient is in imminent danger. The colon may become, from absence of the usual resistance of its muscular coats, very rapidly distended; such distension, besides causing much distress, produces pressure on the diaphragm, impeding its action, and embarrassing that of the heart and lungs. Such pressure, if not relieved, is likely to cause death; for be it borne in mind, it occurs only in the advanced stages of bad cases in which the typhoid state is marked, the cardiac systole feeble, and in which the addition to the already existing troubles of any other complication readily turns the scale against the patient.

Such extreme distension of the colon, with its attending dangers, may be developed very rapidly. It calls for prompt treatment. To give enemata is useless; for the muscular coat of the bowel is so distended that it cannot act. Nay, it is worse than useless ; for it is only adding to the contents of an over-distended bowel. There are only two ways of giving relief--to tap the colon by a fine trocar, or to pass a long tube into it by the rectum. The former proceeding, though attended with very little danger, cannot be said to be free from risk. The passing of a long tube up the bowel is not only void of all danger, but, as a means of relief, is much more speedy and efficacious; for not only does the flatus pass away more readily and freely through the tube than through a cannula, but there passes away with it much of those putrid and sloughy contents of the bowel, whose retention and decomposition cause the whole mischief. The following cases illustrate the beneficial effects of this method of treatment.

CASE 1.-A gentleman, aged thirty-six, of full habit and previous good health, had a severe attack of typhoid fever. Tympanites became a marked symptom early in the third week, and by the eighteenth and nineteenth days it was sufficiently great to increase the patient's restlessness and to cause some anxiety. Enemata of turpentine had been given without affording any relief. On the twentieth day there was great distension of the abdomen, the skin being quite tight; the patient was wandering and very restless; breathing was short and hurried, 42 per minute; pulse 120 , feeble; temperature $103 \cdot 4^{\circ}$. The tongue was dry in the centre; there was slight hiccough. A little darkcoloured freal discharge, with some flatus, was passed involuntarily in bed. Nourishment and brandy were taken frequently and in small quantity, and were occasionally rejected. The patient was much distressed and in imminent danger. A long tube was without difficulty passed in to the bowel; there at once passed away a large quantity of flatus, and about a pint of dark-coloured, liquid, frecal matter, having seattered through it a number of shreddy particles, evidently the remains of sloughs. The patient seemed much relieved. Half an hour after it was noted that he was quieter and much less restless, the abdomen was less tense, the respiration had fallen to 36 , the pulse was 116 , and the temperature had dropped to $102 \cdot 2^{\circ}$. This was at $4 \mathrm{P}, \mathrm{BC}$. At 10 o'clock the temperature was $102 \cdot 8^{\circ}$; pulse 116 ; respiration 36. The tube was again passed; a good deal of flatus and a small amount of dark fiuid asisn coming away through it. The patient passed a better though still restless night. On the following morntng there was some return of the abdominal distension and the restlessness, though neither was so marked as before; the tube was again passed with a like result, a large quantity of flatus came away, followed by neariy a pint of dark fluid frees with sloughy shreds scattered through it. For several days the tube was passed three times a day; by this means the distension was kept down, the bowel was relieved of its offensive contents, and the patient was freed from the most pressing danger. Coincidentally with the relief thus afforded there took place an improvement in his general condition. The pulse, temperature, and respiration all fell after the tnbe was used for the first time, and never again rose to the same point hiccough ceased entirely, and the patient retained all his nourishment. On the twenty-ninth day of the fever there was a marked fall of the temperature and a little all-round improvement; the abdomen was less full; the expression was improved; the tongue was moist all over. On the thirtieth day, the improvement was maintained, and on the morning of the thirty-first day the temperature reached the normal. From this time progress was uninterrupted.

CASE 2.-Miss L-, aged twenty, had a severe attack of typhoid, with all the symptoms well marked. In the fifth week of the disease the abdominal distension, which had been a sufficiently noticeable feature for some time, became rapidly very great, and the patient was extremeiy distressed and apparently sinking. When I saw her there was great distension of the abdomen, the skin of which was quite tense; the patient was prostrate and wandering, restless, and breathing in a distressed and irregular manner, abont 44 per minute; the pulse was 128 , feeble; the cemperature $103.9^{\circ}$. She was evidently suffering from pressure on the diaphragm. There was no long tube at hand, and matters were uryent. so I cut the valvular extremity off from the tube of a Higginson's syringe, and introduced the tube into the bowel as far as the ball. There passed away a great quantity of flatus with abont a pint of clark lignid freces with a number of sloughy-looking shreds floating about in it. The patient was at once much relieved; she became less restless, the respiration dropped to 36 , and became more regular, the pulse improved, and the tempeture fell to $102^{\circ}$, a fall of nearly two degrees, within an hour after the passage of the tribe. A proper tube was obtained, and passed several times daily for nexly a weel. The patient slowly improved, and made after $2 \mathrm{log} g$ time $a$ perfect recovery.

CASE 3.-A young man, aged twenty-three, had much abdominal distension in the third week of un attack of typhoid. On the twenty-first day there was extreme distension and great prostration, with muttering delirium, dry tongue, feeble pulse, and a temperature of $104^{\circ} 1^{\circ}$. The abdominal distension had rapidly increased, and its increase was accompanied by a corresponding prominence in the urgent srmptoms. He was restless, muttering, very prostrate, and rejected all nourishment. A long tube was passed into the bowel. There at once came away a large quantity of flatus and dark-coloured fluid feces, with here and there shreds of sloughy-looking matter seattered through it. All the urgent symptoms were distinctly relieved, the temperature in half an hour fell to $108 \cdot 2^{\circ}$, nourishment was again retained, and he slowly gained ground, though the tube had again to be used on several occasions. The abdominal distension never became again a source of anxiety; but the case continued in rather a severe form till the patient died of perforation on the twenty-ninth day of the disease.

In the first and second cases I beliere that the timely passage of the tube saved the patients' lives, for in neither could the pressure on the diaphragm have gone on for many hours longer without causing death. Many cases there are, of course, in which the passage of the tube, thongh it relieves the urgent symptom for the relief of which it was used, cannot save the patient from the other dangers of the disease. By relieving the pressure on the diaphragm, however, it sares him from that danger, and gives him one more chance of life. Case 3 illustrates this.

Calrgan-place, s.W. 